\title{
Concentration-dependent Differences in Urinary lodine Measurements Between Inductively Coupled Plasma Mass Spectrometry and the Sandell-Kolthoff Method
}

\author{
Yongze $\mathrm{Li}^{1} \cdot$ Shuangning Ding ${ }^{1} \cdot$ Cheng Han ${ }^{1,2} \cdot$ Aihua Liu ${ }^{1,3} \cdot$ Zhongyan Shan $^{1} \cdot$ Weiping Teng ${ }^{1}$ Jinyuan Mao ${ }^{1}$
}

Received: 1 June 2020 / Accepted: 8 September 2020 / Published online: 9 October 2020

(C) The Author(s) 2020

\begin{abstract}
A large amount of historical data regarding urinary iodine concentration (UIC) were measured with the Sandell-Kolthoff (S-K) method for iodine nutrition surveillance. The congruence in urinary iodine measurements between inductively coupled plasma mass spectrometry (ICP-MS) and the S-K method has been debated. A total of 2064 adult urine samples were included in the present study. The UIC measurement results obtained simultaneously by standardized ICP-MS and the S-K method were analyzed. The UIC obtained with ICP-MS was significantly higher than that obtained with the S-K method $(158 \mu \mathrm{g} / \mathrm{L}$ vs. $148 \mu \mathrm{g} / \mathrm{L}, p<0.001)$. The Bland-Altman difference plot showed a small but significant mean difference of $6.12 \mu \mathrm{g} / \mathrm{L}$ between the two methods. The stratified analysis showed that the correlation coefficient was higher in the UIC $<300 \mu \mathrm{g} / \mathrm{L}$ group than the UIC $\geq 300 \mu \mathrm{g} / \mathrm{L}$ group $(0.93 \mathrm{vs.} 0.88, p=0.0001)$. The mean difference between the S-K and ICP-MS methods was positively correlated with the UIC. The ICP-MS and S-K methods were comparable when the UIC was less than $300 \mu \mathrm{g} / \mathrm{L}$; however, UIC values between 300 and $600 \mu \mathrm{g} / \mathrm{L}$ should be compared with caution after considering the research objective. We do not suggest comparing UICs obtained from the ICP-MS and S-K methods in iodine monitoring studies if the UIC is greater than $600 \mu \mathrm{g} / \mathrm{L}$.
\end{abstract}

Keywords Urinary iodine concentration · Inductively coupled plasma mass spectrometry · Sandell-Kolthoff reaction

\section{Introduction}

Iodine is an essential component of thyroid hormones and normally obtained by the consumption of foods that contain iodine or iodized salt, and either low or high iodine intake may lead to thyroid disorders [1]. Iodine supplementation and monitoring programs have been implemented in most countries [2-4]. Urinary iodine concentration (UIC) reflects the

Electronic supplementary material The online version of this article (https://doi.org/10.1007/s12011-020-02381-8) contains supplementary material, which is available to authorized users.

Jinyuan Mao

jinyuanmao@hotmail.com

1 Department of Endocrinology and Metabolism and the Institute of Endocrinology, First Hospital of China Medical University, No.155 Nanjing Bei Street, Shenyang 110001, Liaoning, China

2 Department of Molecular Pharmacology, Albert Einstein College of Medicine, 1300 Morris Park Avenue, Forchheimer 216, The Bronx, NY, USA

3 Department of Endocrinology and Metabolism, Peking University Third Hospital, Beijing, China dietary iodine intake and has been used as a marker for iodine status in population studies $[5,6]$.

Different techniques for the determination of urinary iodine, such as chemical methods and inductively coupled plasma mass spectrometry (ICP-MS), have been developed [7]. At present, UIC is commonly determined spectrophotometrically using the Sandell-Kolthoff reaction (S$\mathrm{K}$ ), or by ICP-MS [8]. The S-K method is cumbersome and time consuming, with significant chemical hazards such as arsenic and cerium. Additionally, as the S-K method relies on chemical kinetics for determination of iodine concentration, the assay is susceptible to form organic species which may chelate cerium and alter the reaction rate $[9,10]$. The ICP-MS method is fast and accurate, offers precision that is equal to the $\mathrm{S}-\mathrm{K}$ method, enables easier sample preparation, and has the potential for simultaneous multielement analysis [11].

At present, ICP-MS is considered the international standard for UIC; however, a considerable amount of historical data was acquired using the S-K method. For a valid comparison of modern data to results from historical studies, correlation studies must be performed for these two analytical methods [12]. 
Although the variation in iodine status of the population is not great and ranges from 50 to $300 \mu \mathrm{g} / \mathrm{L}$, random urine iodine levels between individuals and within each individual vary greatly from 10 to $1000 \mu \mathrm{g} / \mathrm{L}$ [6]. The limitation of the S-K method is that the upper limit of the linear range of the standard curve is $300 \mu \mathrm{g} / \mathrm{L}$; if the sample is above this value, it needs to be diluted and retested, and the process of dilution may affect the accuracy of the results [13]. A few reports have investigated whether the results of the two methods differ [11, 13-15]; however, the sample sizes of the studies were mostly less than 100 individuals, and the studies did not stratify for different levels of UICs.

Understanding the status of iodine nutrition among the population is important for designing proper interventions to reduce the iodine deficiency epidemic [6]. The objective of this study was to assess the consistency of the ICP-MS and S$\mathrm{K}$ methods, especially at different levels of UICs, and to provide evidence for the future prevention and control of iodine nutrition on the basis of historical data.

\section{Materials and Methods}

\section{Study Population}

This study population was partially derived from the TIDE project (Thyroid disorders, Iodine Status and Diabetes: a National Epidemiological Survey) as previously described $[16,17]$. A total of 2064 frozen urine samples from local residents were included in the study to cover a range of concentrations. The study was established in 2014 and approved by the Ethics Committee of China Medical University. The study adhered to the recommendations of the Declaration of Helsinki, and individuals aged more than 18 years who were not pregnant were included. All subjects provided written informed consent following a thorough explanation of the research procedures.

\section{Sandell-Kolthoff Measurements}

The S-K method according to WS/T 107-2006 by ammonium persulfate digestion ( $\mathrm{As}^{3+}-\mathrm{Ce}^{4+}$ catalytic spectrophotometry) was previously described (supplemental material) [18]. All chemicals were supplied by the Sinopharm Chemical Reagent Co., Ltd., China. All samples were measured using a UV-1600 spectrophotometer (Ruili Analytical Instrument Group Co., Ltd., China). A calibration curve was established with $0,50,100,150,200,250$, and $300 \mu \mathrm{g} / \mathrm{L}$ standard solutions. If the UIC of samples were ranged from 300 to 600 $\mu \mathrm{g} / \mathrm{L}$, the urine samples were double diluted by deionized water $(1: 1,250 \mu \mathrm{L}$ of sample plus $250 \mu \mathrm{L}$ of deionized water); if they ranged from 600 to $1200 \mu \mathrm{g} / \mathrm{L}$, they were quadruple diluted $(1: 3,250 \mu \mathrm{L}$ of sample plus $750 \mu \mathrm{L}$ of deionized water), and then $250 \mu \mathrm{L}$ diluted samples were digested and retested. The intra- and interassay coefficients of variation for the UICs were 3 to $4 \%$ and 4 to $6 \%$ at $66 \mu \mathrm{g} / \mathrm{L}$ and 2 to $5 \%$ and 3 to $6 \%$ at $230 \mu \mathrm{g} / \mathrm{L}$, respectively.

\section{ICP-MS Measurement}

UICs were determined using an Agilent® ICP mass spectrometer (Agilent 7700x, Agilent Technologies, USA). The collision mode with an octopole reaction system was used. The measurement method was described previously [11]. The diluent was composed of $1 \%$ tetramethylammonium hydroxide (Maya Reagent, Jiaxing, China), $0.01 \%$ Triton-X 100 (Sinopharm Chemical Reagent Co., Ltd., Shanghai, China), and 10 $\mu \mathrm{g} / \mathrm{L}$ tellurium (Guobiao Testing \& Certification Co., Ltd., Beijing, China) as an internal standard. The concentrations of the intermediate working calibrators were $0,10,25,50,100,200,300,400,800$, and $1000 \mu \mathrm{g} / \mathrm{L}$ to establish a calibration curve. Urine samples and working calibrators were diluted by $1: 10(500 \mu \mathrm{L}$ of sample/calibrator plus $4500 \mu \mathrm{L}$ of diluent). The certified reference materials (GBW09108, GBW09109, and GBW09110) were purchased from Guobiao Testing \& Certification Co., Ltd. (Beijing, China), and their target values were $70.8 \mu \mathrm{g} / \mathrm{L}, 143 \mu \mathrm{g} / \mathrm{L}$, and $224 \mu \mathrm{g} / \mathrm{L}$, respectively. The intraassay coefficients of variance were $2.3 \%, 1.4 \%$, and $2.3 \%$ for GBW09108, GBW09109, and GBW09110, respectively, and the corresponding interassay coefficients of variance were $2.7 \%, 2.5 \%$, and $2.4 \%$, respectively.

\section{Statistical Methods}

All statistical analyses were performed using SPSS Statistics for Windows version 22.0 (Chicago, IL, USA) and MedCalc Statistical Software version 15.6 (Ostend, Belgium), and $p$ values at $<0.05$ were considered significant. The chi-square test was used to test for differences between categorical variables. The data were tested for normality using the Kolmogorov-Smirnov test. The UICs obtained with either method were not normally distributed; therefore, the medians and interquartile ranges (IQRs) were reported, and Spearman correlation and nonparametric tests were performed. PassingBablok correlations and Bland-Altman difference plots were used to assess the agreement between results obtained by the ICP-MS and S-K methods. The samples were stratified by UIC as measured by the S-K method into $<300 \mu \mathrm{g} / \mathrm{L}, \geq 300$ $\mu \mathrm{g} / \mathrm{L}, 300-600 \mu \mathrm{g} / \mathrm{L}$, and $>600 \mu \mathrm{g} / \mathrm{L}$ groups since the urine samples were diluted if the UIC was higher than $300 \mu \mathrm{g} / \mathrm{L}$. Severe iodine deficiency was defined as UIC $<20 \mu \mathrm{g} / \mathrm{L}$, and iodine deficiency was defined as UIC $<100 \mu \mathrm{g} / \mathrm{L}$ [19]. 
Table 1 Comparison of UICs $(\mu \mathrm{g} / \mathrm{L})$ measured by the $\mathrm{S}-\mathrm{K}$ and ICP-MS methods

\begin{tabular}{lllll}
\hline Group & $N(\%)$ & $\begin{array}{l}\text { ICP-MS } \\
\text { Median (IQR) }\end{array}$ & $\begin{array}{l}\text { S-K } \\
\text { Median (IQR) }\end{array}$ & $p$ value $^{\mathrm{a}}$ \\
\hline $\begin{array}{l}\text { Total } \\
\text { Groups sorted by UIC using the S-K method }\end{array}$ & $158(101,245)$ & $148(96,223)$ & $<0.0001$ \\
$<300 \mu \mathrm{g} / \mathrm{L}$ & $1816(87.98)$ & $142(94,204)$ & $135(91,191)$ & $<0.0001$ \\
$\geq 300 \mu \mathrm{g} / \mathrm{L}$ & $248(12.02)$ & $437(370,541)$ & $456(389,585)$ & $<0.0001$ \\
$300-600 \mu \mathrm{g} / \mathrm{L}$ & $193(9.35)$ & $408(349,463)$ & $424(355,479)$ & 0.0004 \\
$>600 \mu \mathrm{g} / \mathrm{L}$ & $55(2.66)$ & $683(587,792)$ & $768(664,866)$ & $<0.0001$ \\
\hline
\end{tabular}

${ }^{\text {a }}$ Comparison of UICs measured by the S-K and ICP-MS methods with the Wilcoxon test

\section{Results}

Data were available for 2064 samples. The mean age of the adults was 45.73 years old (SD 14.65), and $38.67 \%$ were men. The prevalence of severe iodine deficiency labeled by the S-K and ICP-MS method was $0.48 \%$ and $0.53 \%\left(X^{2}=0.048, p=\right.$ $0.83)$, respectively. The prevalence of iodine deficiency labeled by the S-K method was significantly higher than those labeled by the ICP-MS method $(27.62 \%$ vs. $24.81 \%, p=$ $0.04)$. Table 1 shows the UICs of the subjects as measured by the ICP-MS and the S-K methods. The UICs of the ICPMS method ranged from 6 to $1124 \mu \mathrm{g} / \mathrm{L}$ (median: $158 \mu \mathrm{g} / \mathrm{L}$; IQR: 101-245 $\mu \mathrm{g} / \mathrm{L})$. The corresponding values of the $\mathrm{S}-\mathrm{K}$ method showed similar results, with UICs ranging from 5 to $1189 \mu \mathrm{g} / \mathrm{L}$ (median: $148 \mu \mathrm{g} / \mathrm{L}$; IQR: 96-223 $\mu \mathrm{g} / \mathrm{L}$ ). The measurement values obtained with the ICP-MS method were significantly higher than those obtained with the S-K method $(158 \mu \mathrm{g} / \mathrm{L}$ vs. $148 \mu \mathrm{g} / \mathrm{L}, p<0.001)$.

When the UIC was $<300 \mu \mathrm{g} / \mathrm{L}$, the UIC obtained by ICPMS was significantly higher than that obtained by the S-K method $(142 \mu \mathrm{g} / \mathrm{L}$ vs. $135 \mu \mathrm{g} / \mathrm{L}, p<0.001)$. However, when the UIC was between 300 and $600 \mu \mathrm{g} / \mathrm{L}$ and greater than 600 $\mu \mathrm{g} / \mathrm{L}$, the UIC obtained by the ICP-MS method was significantly lower than that obtained by the S-K method $(408 \mu \mathrm{g} / \mathrm{L}$ vs. $424 \mu \mathrm{g} / \mathrm{L}, p=0.0004$ and $683 \mu \mathrm{g} / \mathrm{L}$ vs. $768 \mu \mathrm{g} / \mathrm{L}, p<$ 0.0001 , respectively).

The Passing-Bablok regression (Fig. 1) showed a very strong correlation between the two methods. The PassingBablok regression equation for both methods was $y=0.22+$ 1.05x (x: S-K method; y: ICP-MS method). Constant differences were evaluated by calculating the intercept of the regression within the $95 \%$ CI (intercept: 0.22 , 95\% CI: -1.89 to 1.98). The slope was 1.05 (95\% CI: 1.03 to 1.06 ), and Spearman's correlation coefficient was 0.95 (95\% CI: 0.945-0.954, $p<0.001)$.

The Bland-Altman plot (Fig. 2) for the UICs obtained by the ICP-MS and S-K method showed that the mean difference line was at $6.12 \mu \mathrm{g} / \mathrm{L}$ (95\% CI: 4.40 to $7.85 \mu \mathrm{g} / \mathrm{L})$. The differences between the individual results obtained by the two methods were concentration-dependent. The $95 \%$ limit of agreement (i.e., the interval defined by the mean differences \pm 2 SDs) indicated that the variability in the difference between the ICP-MS and S-K results was between - 74.02 and $86.26 \mu \mathrm{g} / \mathrm{L}$.

Stratified analyses of the Passing-Bablok regression and Bland-Altman plot were also conducted based on the UIC levels obtained by the S-K method (Table 2). For UIC < $300 \mu \mathrm{g} / \mathrm{L}$ obtained by the S-K method, Passing-Bablok regression showed a very high congruence between the two methods. The Passing-Bablok regression equation for both methods was $\mathrm{y}=-8.95+1.14 \mathrm{x}$ (x: S-K method; y: ICP-MS method). Spearman's correlation coefficient was 0.93 , which was significantly higher than the corresponding value in the UIC $\geq 300 \mu \mathrm{g} / \mathrm{L}$ group $(p<0.0001)$ (Table 2). The differences between the individual results obtained by the two methods showed a small but significant mean difference of $10.85 \mu \mathrm{g} / \mathrm{L}(95 \% \mathrm{CI}: 9.40$ to $12.30 \mu \mathrm{g} / \mathrm{L})$ between the two methods.

For the UICs ranging from 300 to $600 \mu \mathrm{g} / \mathrm{L}$ obtained by the $\mathrm{S}-\mathrm{K}$ method, the Passing-Bablok regression showed a high congruence between the two methods. The Passing-Bablok regression equation for both methods was $\mathrm{y}=-9.02+$ 0.99x (x: S-K method; y: ICP-MS method). Spearman's correlation coefficient was $0.78(p<0.0001)$, which was significantly lower than the corresponding value of 0.93 in the UIC $<300 \mu \mathrm{g} / \mathrm{L}$ group. The differences between the individual results obtained by the two methods showed a small but significant mean difference of $-15.58 \mu \mathrm{g} / \mathrm{L}$ (95\% CI: -23.92 to $-7.25 \mu \mathrm{g} / \mathrm{L})$.

For the UICs $>600 \mu \mathrm{g} / \mathrm{L}$ values obtained by the S-K method, the Passing-Bablok regression showed a high congruence between the two methods. The Passing-Bablok regression equation for both methods was $\mathrm{y}=-154.71+1.10 \mathrm{x}(\mathrm{x}$ : SK method; y: ICP-MS method). Spearman's correlation coefficient was $0.84(p<0.0001)$. The differences between the individual results obtained by the two methods showed a significant mean difference of $-73.75 \mu \mathrm{g} / \mathrm{L}$ (95\% CI: -96.18 to $-51.33 \mu \mathrm{g} / \mathrm{L})$. 


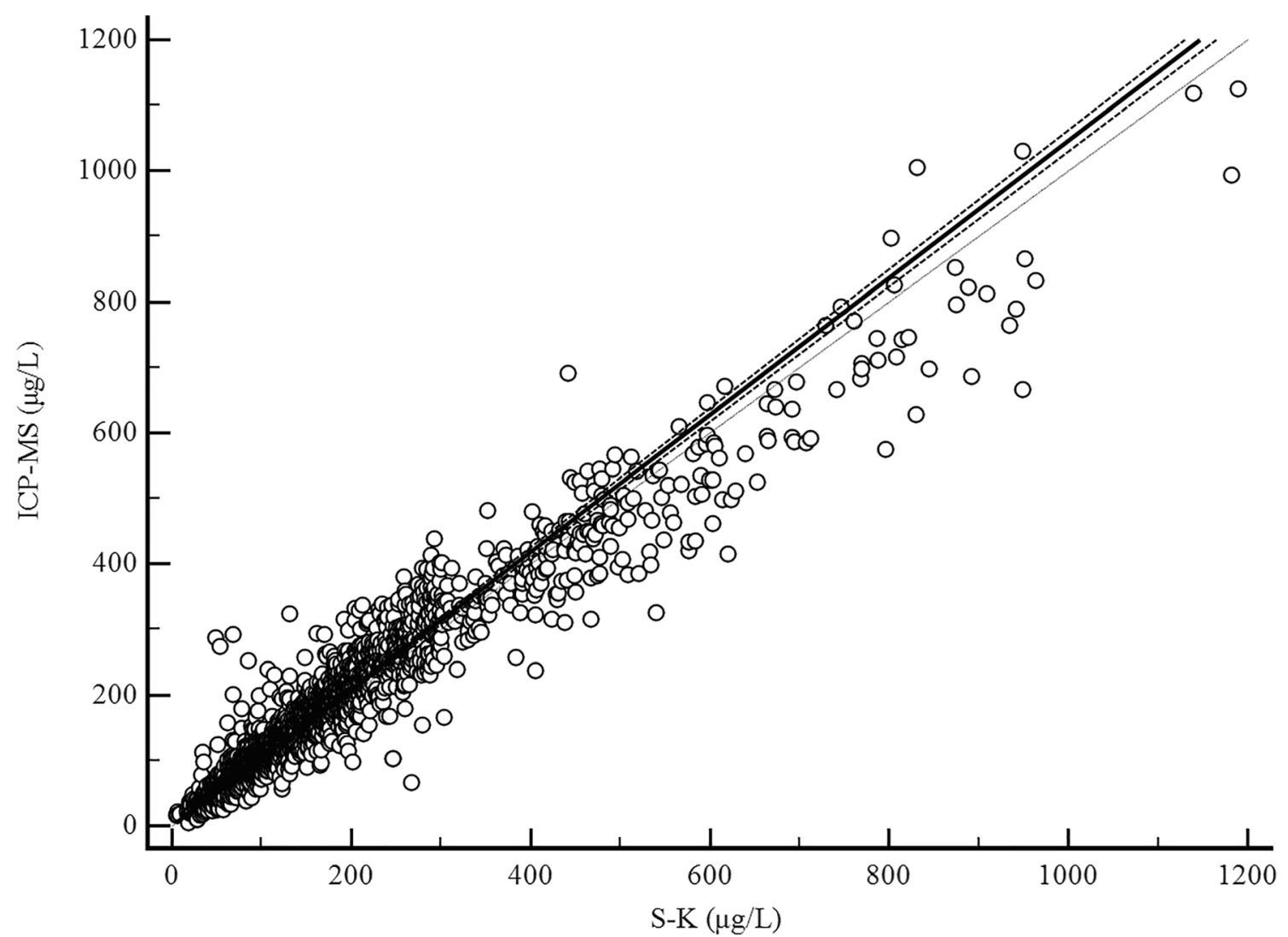

Fig. 1 Comparison of the ICP-MS and S-K methods using the Passing-Bablok regression for the total population. The solid line represents regression line, the bold dashed line represents confidence interval, and the dotted line represents diagonal

\section{Discussion}

Detection of urine iodine using the S-K method has been widely used in previous iodine nutrition monitoring; however, it requires tedious preparation of the sample before determination. The sensitivity, linearity, and reproducibility of the ICP-MS method have been proven sufficient to determine iodine concentrations in human plasma and urine [20,21]. In our study, we observed a strong congruence between the ICP-MS and S-K methods in the whole population. The coefficients of the slope (test for slope $=1$ ) differed significantly between the two methods, although the regression line was close to the bisectrix. A possible explanation was the concentration-dependent differences in the two methods, which were consistent with a previous study [11]. The Bland-Altman plot showed that the UIC measured by ICPMS was $6.12 \mu \mathrm{g} / \mathrm{L}$ higher than that measured by the S-K method. That difference was acceptable in clinical examination; therefore, we considered that the S-K and ICP-MS methods showed good congruence and the test results of the two methods could be compared directly. The difference in the UIC $<300 \mu \mathrm{g} / \mathrm{L}$ results obtained by the S-K method compared with the ICP-MS method might be partly explained by the weak oxidation capacity of ammonium persulfate compared with perchloric acid because iodide needs to be rapidly and effectively oxidized to iodate to prevent the iodine from volatilization before photometric measurement through the S$\mathrm{K}$ reaction [15].

In addition, we found that the UIC measured by ICP-MS was higher than that measured by the S-K method for UIC < $300 \mu \mathrm{g} / \mathrm{L}$, which was different compared with previous studies $[11,14]$. This finding might be due to a small sample size in the previous study that led to insufficient power to detect significant differences. In addition, each method considers a different set of parameters and has a slightly different standard operation procedure. However, the UIC obtained by the S-K method was higher than that obtained by ICP-MS for UIC $\geq$ $300 \mu \mathrm{g} / \mathrm{L}$, which may be due to urine sample dilution for the $\mathrm{S}-\mathrm{K}$ method. The possible explanations are as follows: urine samples contain iodine (which we are interested in) and sundry organics, proteins, amino acids (which we are not interested in and may interfere with the S-K reaction). Interfering species may slow the generation of the cerium chromophore, making a sample appear to have less iodine that it the true value. The samples of UIC $\geq 300 \mu \mathrm{g} / \mathrm{L}$ are double or quadruple diluted before digestion. As we dilute the iodine target in the samples, we are also diluting the interfering species that slow the S-K reaction, so the reaction speeds up and the measured value of iodine increases. The same samples tested by ICP-MS are diluted in a constant manner, not varying with 


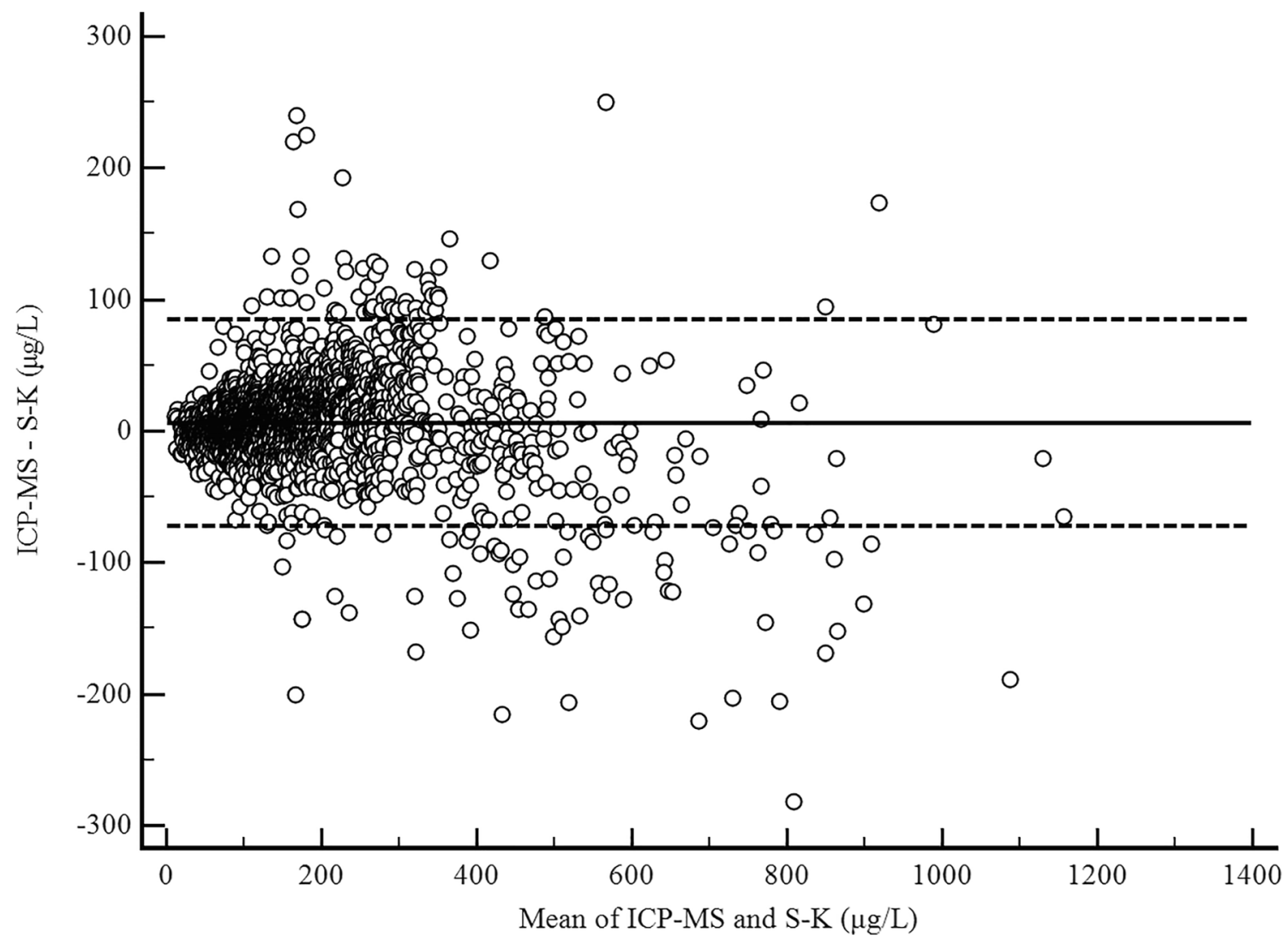

Fig. 2 Comparison of the ICP-MS and S-K methods with the Bland-Altman plot for the total population. The solid line represents the mean difference, and the dashed line represents the $95 \%$ limit of agreement

sample concentration. In addition, we noticed that the greater the dilution the larger the deviation. When the UIC ranged from 300 to $600 \mu \mathrm{g} / \mathrm{L}$, the mean difference between the two methods was $15.58 \mu \mathrm{g} / \mathrm{L}$; and when UIC $\geq 600 \mu \mathrm{g} / \mathrm{L}$, the mean difference reached $73.75 \mu \mathrm{g} / \mathrm{L}$, which was unacceptable for clinical examination.
Differences in the UIC measurements may have been caused by a number of reasons, and the following factors may have played a relevant role. The urine matrix was diluted by water, and a previous study showed that test values obtained by the S-K method for high-UIC samples diluted by water were significantly higher than for low-UIC samples after
Table 2 Parameters of PassingBablok regression, Bland-Altman plot, and Spearman's correlation

\begin{tabular}{|c|c|c|c|c|c|c|}
\hline \multirow{2}{*}{$\begin{array}{l}\text { UIC of the S- } \\
\text { K method }\end{array}$} & \multicolumn{2}{|c|}{ Passing-Bablok regression } & \multicolumn{2}{|c|}{ Bland-Altman plot } & \multicolumn{2}{|c|}{ Spearman's correlation } \\
\hline & $\begin{array}{l}\text { Slope } \\
(95 \% \mathrm{CI})\end{array}$ & $\begin{array}{l}\text { Intercept } \\
(95 \% \mathrm{CI})\end{array}$ & $\begin{array}{l}\text { Mean } \\
\text { difference } \\
(95 \% \mathrm{CI})\end{array}$ & $\begin{array}{l}95 \% \text { limits of } \\
\text { agreement }\end{array}$ & $\begin{array}{l}\text { Correlation } \\
\text { coefficient } \\
(95 \% \mathrm{CI})\end{array}$ & $\begin{array}{l}p \\
\text { value }\end{array}$ \\
\hline$<300 \mu \mathrm{g} / \mathrm{L}$ & $\begin{array}{l}1.14 \\
(1.12-1.15)\end{array}$ & $\begin{array}{l}-8.95 \\
(-11.05 \text { to }- \\
6.74)\end{array}$ & $\begin{array}{l}10.85 \\
(9.40-12.30)\end{array}$ & $-52.07-73.77$ & $\begin{array}{l}0.93 \\
(0.92-0.93)\end{array}$ & $\begin{array}{l}< \\
0.0- \\
001\end{array}$ \\
\hline$\geq 300 \mu \mathrm{g} / \mathrm{L}$ & $\begin{array}{l}0.89 \\
(0.84-0.95)\end{array}$ & $\begin{array}{l}31.55 \\
(6.70-52.65)\end{array}$ & $\begin{array}{l}-28.49 \\
(-37.12 \text { to }- \\
19.85)\end{array}$ & $\begin{array}{l}- \\
166.61-109- \\
.63\end{array}$ & $\begin{array}{l}0.88 \\
(0.85-0.91)\end{array}$ & $\begin{array}{l}< \\
0.0- \\
001\end{array}$ \\
\hline $300-600 \mu \mathrm{g} / \mathrm{L}$ & $\begin{array}{l}0.99 \\
(0.90-1.10)\end{array}$ & $\begin{array}{l}-9.02 \\
(- \\
52.90-31 .- \\
03)\end{array}$ & $\begin{array}{l}-15.58 \\
(-23.92 \text { to }- \\
7.25)\end{array}$ & $\begin{array}{l}- \\
133.00-101- \\
.84\end{array}$ & $\begin{array}{l}0.78 \\
(0.71-0.83)\end{array}$ & $\begin{array}{r}< \\
0.0- \\
001\end{array}$ \\
\hline$>600 \mu \mathrm{g} / \mathrm{L}$ & $\begin{array}{l}1.10 \\
(0.94-1.30)\end{array}$ & $\begin{array}{c}-154.71 \\
(-304.34 \text { to } \\
-25.30)\end{array}$ & $\begin{array}{l}-73.75 \\
(-96.18 \text { to }- \\
51.33)\end{array}$ & $\begin{array}{l}- \\
239.65-92 .- \\
15\end{array}$ & $\begin{array}{l}0.84 \\
(0.74-0.91)\end{array}$ & $\begin{array}{l}< \\
0.0- \\
001\end{array}$ \\
\hline
\end{tabular}


dilution [22]. Another study showed that insufficient oxidants resulted in false high concentrations of pseudoiodine in urine due to interference with the incomplete ashed urine composition [23]. This variation could have implications for public health because monitoring for iodine-fortification programs usually focuses on the median UIC in the population. In the NHANES III conducted in 1988-1994, the median UIC of the population was $144.7 \mu \mathrm{g} / \mathrm{L}$ with the S-K method; however, in the NHANES 2001-2002, this value increased to $167.8 \mu \mathrm{g} / \mathrm{L}$ with the ICP-MS method [11]. The differences between the detection methods might have led to this increase to a certain extent, indicating the importance of accurate UIC measurements for adequate public health decisions. However, because the variations are more evident for individuals with excessive iodine intake and iodine fortification programs are more important for people with iodine deficiency, both methods could reliably quantify UICs.

This study is subject to several limitations. First, we could not analyze other potential influencing factors (such as drugs, diseases) that might have affected the results. Second, we did not verify whether the test value obtained by the S-K method for the high-UIC samples diluted by water was significantly higher than that for the low-UIC samples diluted by water, which would be relevant for explaining the observed differences in the UIC measurements. In addition, various digestion methods might lead to different results for the S-K method since we chose only ammonium persulfate as a digestion substance [15].

In conclusion, we demonstrated that the UIC results of the ICP-MS and S-K methods were comparable. In particular, the test results of the two methods could be compared directly when the UIC was less than $300 \mu \mathrm{g} / \mathrm{L}$, which covered the normal adult UIC range. The results for UICs ranging between 300 and $600 \mu \mathrm{g} / \mathrm{L}$ should be compared only with caution after considering the research objective. However, we do not suggest comparing UICs from the ICP-MS and S-K methods in iodine monitoring studies if the UIC is greater than $600 \mu \mathrm{g} / \mathrm{L}$. Further large-scale investigations with standard UIC measurements and adequate power should be conducted to generate a more precise estimate of the conversion formula between the ICP-MS and S-K methods for historical data comparisons.

Acknowledgments We thank all the participants in this study from the TIDE project.

Authors' Contributions YZL, ZYS, WPT, and JYM designed and coordinated the study. YZL, JYM, SND, and CH carried out the sample measurements, data collection, and information classification. JYM and SND were responsible for quality control. YZL and JYM analyzed the data and drafted the manuscript. YZL and AHL revised the manuscript. AHL revised the language. All authors have read and approved the final manuscript.

Funding This work was supported by the Research Fund for Public Welfare from the National Health and Family Planning Commission of China (Grant No. 201402005), the Chinese National Natural Science
Foundation (Grant No. 8170031476), and the China Medical University Youth Support Program (Grant No. QGZD2018036).

Compliance with Ethical Standards The study was established in 2014 and approved by the Ethics Committee of China Medical University.

Competing Interests The authors declare that they have no conflicts of interest.

Open Access This article is licensed under a Creative Commons Attribution 4.0 International License, which permits use, sharing, adaptation, distribution and reproduction in any medium or format, as long as you give appropriate credit to the original author(s) and the source, provide a link to the Creative Commons licence, and indicate if changes were made. The images or other third party material in this article are included in the article's Creative Commons licence, unless indicated otherwise in a credit line to the material. If material is not included in the article's Creative Commons licence and your intended use is not permitted by statutory regulation or exceeds the permitted use, you will need to obtain permission directly from the copyright holder. To view a copy of this licence, visit http://creativecommons.org/licenses/by/4.0/.

\section{References}

1. Teng W, Shan Z, Teng X, Guan H, Li Y, Teng D, Jin Y, Yu X, Fan C, Chong W, Yang F, Dai H, Yu Y, Li J, Chen Y, Zhao D, Shi X, Hu F, Mao J, Gu X, Yang R, Tong Y, Wang W, Gao T, Li C (2006) Effect of iodine intake on thyroid diseases in China. N Engl J Med 354(26):2783-2793

2. Todd CH, Allain T, Gomo ZA, Hasler JA, Ndiweni M, Oken E (1995) Increase in thyrotoxicosis associated with iodine supplements in Zimbabwe. Lancet 346(8989):1563-1564

3. Delange F, de Benoist B, Alnwick D (1999) Risks of iodineinduced hyperthyroidism after correction of iodine deficiency by iodized salt. Thyroid 9(6):545-556

4. Bürgi H, Kohler M, Morselli B (1998) Thyrotoxicosis incidence in Switzerland and benefit of improved iodine supply. Lancet 352(9133): 1034

5. ICCIDD (2001) Ideal iodine nutrition: a brief nontechnical guide. IDD Newsletter 17:28-9.

6. WHO, UNICEF, ICCIDD (2008) Assessment of iodine deficiency disorders and monitoring their elimination. A guide for programmemanagers, 3rd edn.

7. Jooste PL, Strydom E (2010) Methods for determination of iodine in urine and salt. Best Pract Res Clin Endocrinol Metab 24(1):7788

8. Shelor CP, Dasgupta PK (2011) Review of analytical methods for the quantification of iodine in complex matrices. Anal Chim Acta 702(1):16-36

9. Sandell EB, Kolthoff IM (1937) Micro determination catalyticmethod. Mikrochem Acta 1:9-25

10. May W, Wu D, Eastman C, Bourdoux P, Maberly G (1990) Evaluation of automated urinary iodine methods: problems of interfering substances identified. Clin Chem 36(6):865

11. Caldwell KL, Maxwell CB, Makhmudov A, Pino S, Braverman LE, Jones RL, Hollowell JG (2003) Use of inductively coupled plasma mass spectrometry to measure urinary iodine in NHANES 2000: comparison with previous method. Clin Chem 49(6 Pt 1): 1019-1021

12. Gunter EW, Lewis BL, Koncikowski SM (1996) Laboratory methods used for the Third National Health and Nutrition 
Examination Survey (NHANES III), 1988-1994. Centers for Disease Control and Prevention, Hyattsville, Mdvii, pp 1-9.

13. Haap M, Roth HJ, Huber T, Dittmann H, Wahl R (2017) Urinary iodine: comparison of a simple method for its determination in microplates with measurement by inductively-coupled plasma mass spectrometry. Sci Rep 7:39835

14. Macours P, Aubry JC, Hauquier B, Boeynaems JM, Goldman S, Moreno-Reyes R (2008) Determination of urinary iodine by inductively coupled plasma mass spectrometry. J Trace Elem Med Biol 22(2):162-165

15. Ittermann T, Johner S, Below H, Leiterer M, Thamm M, Remer T, Völzke H (2018) Interlaboratory variability of urinary iodine measurements. Clin Chem Lab Med 56(3):441-447

16. Li Y, Teng D, Ba J, Chen B, du J, He L, Lai X, Teng X, Shi X, Li Y, Chi H, Liao E, Liu C, Liu L, Qin G, Qin Y, Quan H, Shi B, Sun H, Tang X, Tong N, Wang G, Zhang JA, Wang Y, Xue Y, Yan L, Yang J, Yang L, Yao Y, Ye Z, Zhang Q, Zhang L, Zhu J, Zhu M, Ning G, Mu Y, Zhao J, Shan Z, Teng W (2020) Efficacy and safety of long-term universal salt iodization on thyroid disorders: epidemiological evidence from 31 provinces of mainland China. Thyroid 30(4):568-579

17. Li Y, Teng D, Shi X et al (2020) Prevalence of diabetes recorded in mainland China using 2018 diagnostic criteria from the American Diabetes Association: national cross sectional study. BMJ 369: m997
18. Yang Y, Zhang Y, Liu L et al (2006) Method for determination of iodine in urine by $\mathrm{As}^{3+}-\mathrm{Ce}^{4+}$ catalytic spectrophotometry (WS/T 107-2006). People's Medical Publishing House, Beijing. [In Chinese]

19. International Council for Control of Iodine Deficiency Disorders, UNICEF, World Health Organization (2001) Assessment of iodine deficiency disorders and monitoring their elimination: a guide for programme managers, 2nd edn.

20. Allain P, Mauras Y, Douge C, Jaunault L (1990) Determination of iodine and bromine in plasma and urine by inductively coupled plasma mass spectrometry. Analyst 115:813-815

21. Dunn JT, Crutchfield HE, Gutekunst R, Dunn AD (1993) Two simple methods for measuring iodine in urine. Thyroid 3:119-123

22. Wang F, Liang Y, Yu G et al (2015) Effects of dilution of matrix on determination of iodine in urine. J Environ Health 32(7):629-631 [In Chinese]

23. Pino S, Fang SL, Braverman LE (1996) Ammonium persulfate: a safe alternative oxidizing reagent for measuring urinary iodine. Clin Chem 42(2):239-243

Publisher's Note Springer Nature remains neutral with regard to jurisdictional claims in published maps and institutional affiliations. 